Meta

Journal des traducteurs

Translators' Journal

\title{
The Translator as Rapporteur: A Concept for Training and Self-improvement
}

\section{Brian Mossop}

Volume 28, numéro 3, septembre 1983

URI : https://id.erudit.org/iderudit/003674ar

DOI : https://doi.org/10.7202/003674ar

Aller au sommaire du numéro

Éditeur(s)

Les Presses de l'Université de Montréal

ISSN

0026-0452 (imprimé)

1492-1421 (numérique)

Découvrir la revue

Citer cet article

Mossop, B. (1983). The Translator as Rapporteur: A Concept for Training and

Self-improvement. Meta, 28(3), 244-278. https://doi.org/10.7202/003674ar d'utilisation que vous pouvez consulter en ligne.

https://apropos.erudit.org/fr/usagers/politique-dutilisation/ 


\title{
THE TRANSLATOR AS RAPPORTEUR : A CONCEPT FOR TRAINING AND SELF-IMPROVEMENT
}

\author{
BrIAN Mossop*
}

\section{WHAT ARE TRANSLATORS DOING WHEN THEY TRANSLATE?}

1.1 In my experience as both trainee and trainer, the on-job training and development of translators tends to divorce the question "How do I translate?" from the question "What am I doing when I translate?". The emphasis is on the first question - on technique rather than on purpose. Training centres on revision : source text and translation are compared and weak points in technique are brought out.

But is it enough to point out weaknesses in retrospect, after the translation is done? The important question, it seems to me, is why errors were committed in the first place. And to my mind, the principal cause of error is not mere technical incapacity, a failure to have mastered a certain repertoire of translation techniques. Rather the main problem is that translators are not always in the right frame of mind while translating, and this is so because they have not always sufficiently reflected on just exactly what it is they are doing when they are translating.

1.2 What is a translator doing? Some may see this as a non-question, or a matter for theorists, philosophers and schools of translation, not a practical problem for working translators. Surely, they will say, what the translator is doing is replacing words and sentences of one language with words and sentences of another, preserving meaning.

Some version of this general notion of translation is the one commonly found in diagrammatic representations of the translation process. Stripped down to essentials, it looks like this:

$$
\text { text } x \longrightarrow \text { "meaning" }>\text { text } y
$$

Let us call this Model 1 . It may be read as follows: meaning is extracted from text $\mathrm{x}$ and then a text $\mathrm{y}$ is composed with equivalent meaning.

At first, Model 1 may look like a natural description of translation. But in fact it is deceptive. Most immediately, the deception arises from a difference between speech and writing (and consequently affects translators but not interpreters). When we translate, what we start with is a paper with markings on it

* I would like to thank the following for their suggestions and comments on earlier drafts of this article: Sarah Cummins, Henry A. Gleason Jr., Michael Gregory, Ken Popert, Charles Taber and Agnes Whitfield-Kirschbaum. 
(the source text) and what we end with is another paper with markings on it (the translation). These texts, with their markings which we identify as a sequence of words and sentences, appear to be the fundamental reality for the translator. They are the focus of Model 1.

However this text-focus masks something which is obvious in face-to-face speech: a text, whether spoken or written, is only a part of a social act. An individual or group A is writing to another individual or group B for some specific purpose. The shape of the resulting text is determined in part by the language $\mathrm{A}$ and $\mathrm{B}$ share, in part by the various text-composing habits (the 'rhetorics') of their culture, and in part by the social and personal identities of $\mathrm{A}$ and $\mathrm{B}$ and their purposes on that occasion. $\mathrm{B}$ combines linguistic and rhetorical knowledge with knowledge of the specific occasion at hand (identities, purposes and preceding utterances; aspects of the world with which $\mathrm{A}$ and $\mathrm{B}$ are currently concerned) and assigns some interpretation to what $A$ has written.

Thus meaning is something that resides not in the text but in the interaction between $\mathrm{A}$ and $\mathrm{B}$. Behind words there are always social relations. This is obvious in face-to-face speech where A and B are both present, but it is not so obvious in written discourse. As translators, we are usually sitting at our desks with only a text in front of us. The A and B who go with the text are absent. It is very easy to forget all about them. And it is easy to forget, as we compose the translation, that we ourselves are then As writing to Bs. We may see only words and sentences, and it will be tempting to think of ourselves as text processors engaged in the conversion of these words and sentences into other ('equivalent') words and sentences. It is this view of ourselves that is represented in Model 1.

Now some may think that Model 1 sets up a straw man, a naive layman's idea of translation based on the false assumption that there exist between words and sentences of one language, and those of another, correspondences that are determinable on a purely linguistic basis. Contemporary descriptions of translation, it will be objected, deal at great length with nonlinguistic matters such as culture, function, author's intent, the effect on the reader, and the role of the translator. To meet this objection, we can construct an elaborated version of the model-Model la:

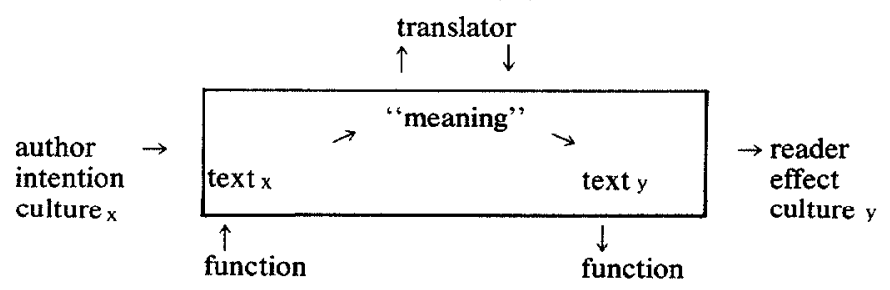

Model la makes it clear that equivalence is not of a purely linguistic nature. With this model, we can speak of the functional or cultural equivalence of texts and the equivalence of effect to intent ${ }^{1}$. But if we are concerned with the

1. A cultural-equivalence approach would perhaps require changing the schema "text $\mathrm{x} \rightarrow$ "meaning' $\rightarrow$ text $y$ " to "text $x \rightarrow$ "meaning $x$ '/ /"meaning $y$ ' $\rightarrow$ text $y$ ", since no one culturally neutral meaning is involved. There can be found in the literature on translation several 
translator's concept of what he or she is doing while translating, there is no really significant difference between Model 1 and Model la, because Model Ia continues to represent the central problem of translation as the search for textual equivalences. For reasons which will be set out in section 3.1, the notion that translating is a process of equivalence-seeking is unhelpful for training or self-improvement purposes (whatever other virtues the concept of equivalence might have). What is needed is a radically different view of the translator's activity, one in which not the texts but the translator and the other participants play the central roles.

1.3 Here is a diagrammatic representation of my proposed alternative:

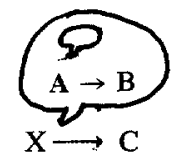

I will call this Model 2, and it may be read as follows: $\mathrm{X}$ reports in writing to $\mathrm{C}$ what A has written to B. (The texts " $x$ " and " $y$ " of Model 1 are now represented through the convention of the cartoonist's bubble-the inner and outer bubbles respectively.)

This model is not specifically a model of translation. The language of the report which $X$ makes to $C$ may or may not be the same as the language $A$ used in writing to $B$. If it is not the same, then the rapporteur: $X$ is a translator. At the centre of the model we find not a pair of texts linked by the equivalence relation, but a social act, the act of reporting something to someone. One act (sourcetext author A writing to source-text reader B) is embedded in another (rapporteur X writing to report reader $\mathrm{C}$ ).

Model 2 makes it clear that translation is not the transfer of a message from one language to another or from one text to another but rather its removal from one complete language-transaction system $(\mathrm{A} \rightarrow \mathrm{B})$ and incorporation into another $(X \rightarrow C)$. The model overcomes two false implications of Model 1a: that the author of the source text is addressing the translator, and that the author of the source text is also addressing the reader ("through" the translator). The translator is, generally speaking, not a member of A's intended audience but an outsider, who so to speak overhears ('overreads') the transaction $\mathrm{A} \rightarrow \mathrm{B}^{2}$, and then reports what he or she has overheard to $C$. And $C$ is also outside the audience of $\mathrm{A}$ (at least as regards language and culture if not subject matter), so that contrary to Model 1a, the source-text author cannot be seen as in some sense the author of the translation, addressing $\mathrm{C}$ through the translator $\mathrm{X}$, with the latter appearing in a merely technical capacity as receiver, recoder and transmitter - an invisible hand behind the scenes rather than a full participant in a social transaction. That is why in Model 2 the translator $X$ is clearly represented as the author of the translation. Specifically,

models more sophisticated than my Model 1 or 1a (see for example Wilss 1977, pages 61-67 and 95-98), but all of them are fundamentally different from the alternative to Model 1 presented in section 1.3 below.

2. Moskowitz (1973) captures this when he says that the translator is not the "destinataire" but rather the "récepteur" of what A has written. 


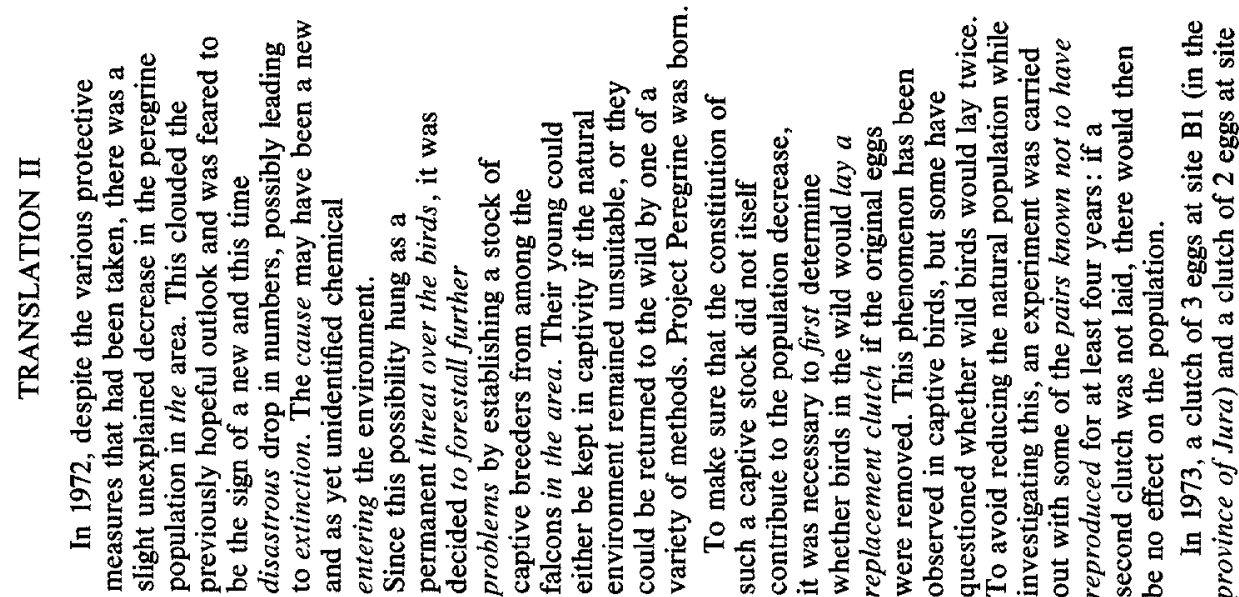

- Nm+non

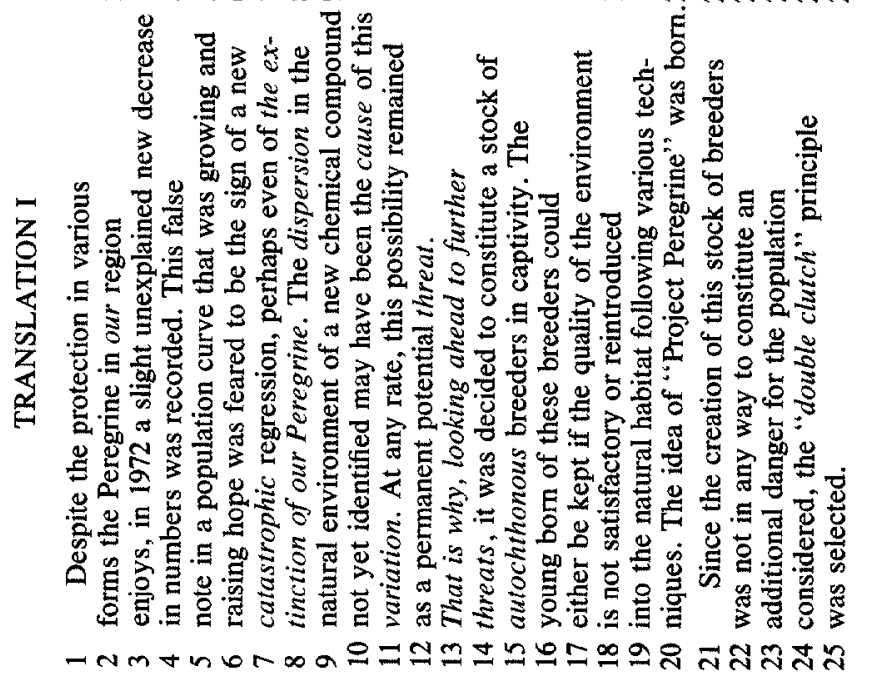

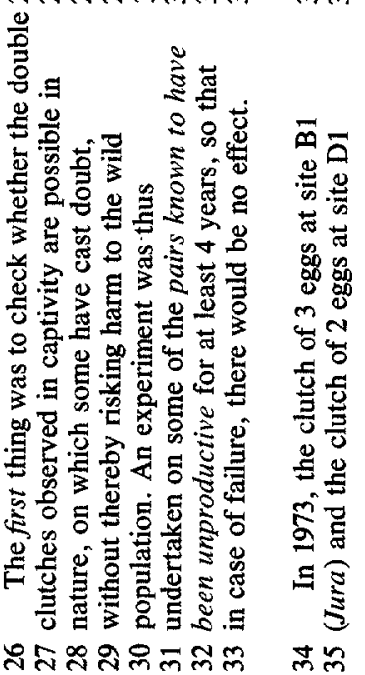

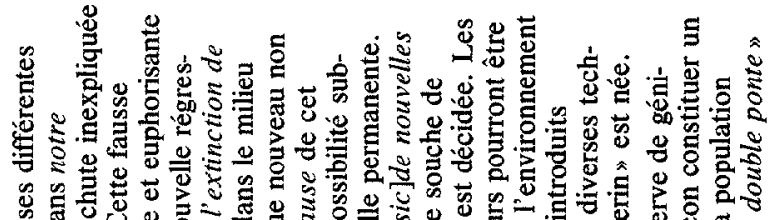

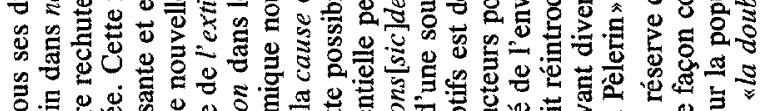

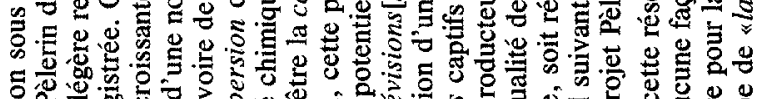

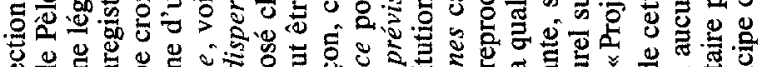

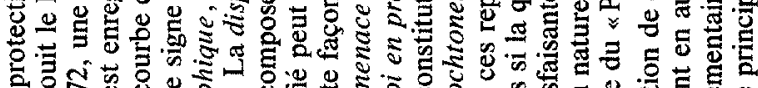

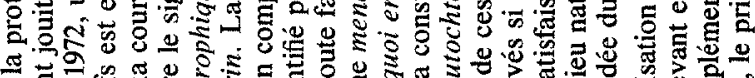

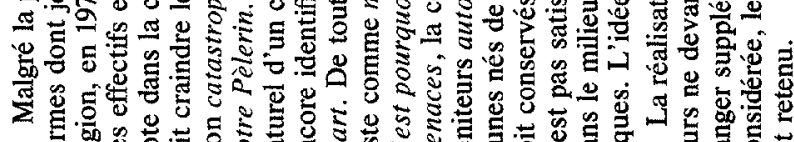

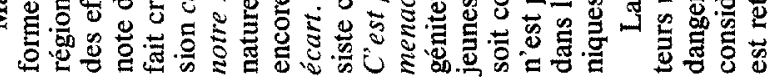




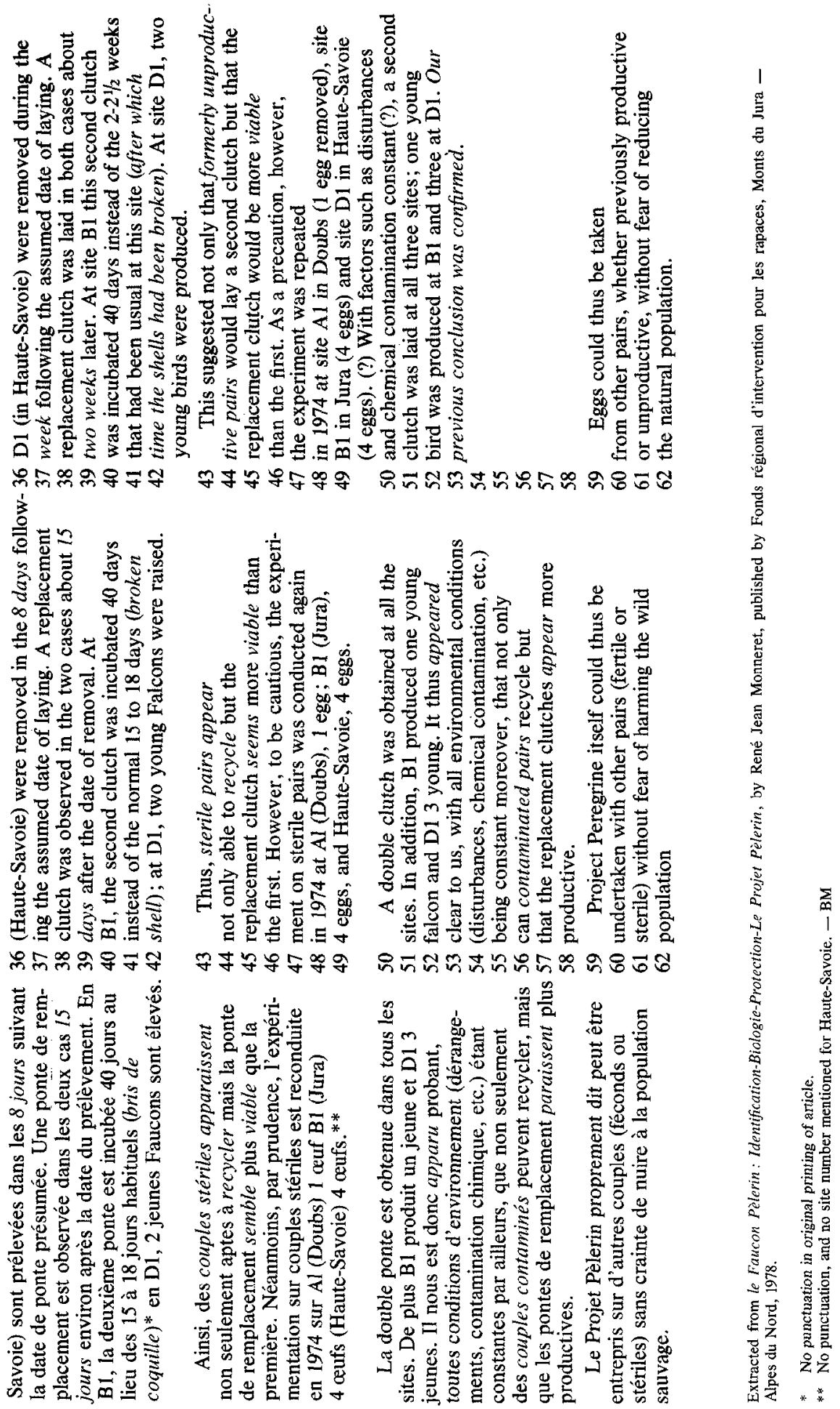


$\mathrm{X}$ is a rapporteur in whose reporting voice we hear embedded the reported voice of $\mathrm{A}$.

Section 2 below provides an initial clarification of the nature of this embedding, through an analysis of the familiar notion of reported discourse. Section 3 elaborates on just what it means for the translator to have a Model-1 self-concept (as an equivalence-seeker), while section 4 looks at the Model-2 alternative, which replaces the Model-1 concept of reexpressing a message by means of an equivalent text with the concept of writing an appropriate report to $C$ on the transaction $A \rightarrow B$. Finally, section 5 describes some sources of resistance to Model 2.

1.4 To concretize the discussion, I will be referring to the French text that is set out below along with two translations into English. Expressions I will be using as examples are italicized. The text is a passage from an article on peregrine falcons written for a conservation society in France and translated at the request of a Canadian government ornithologist working with falcons in British Columbia. Translations I and II are meant to illustrate some of the results of following Models 1 and 2 respectively. In real life, of course, trainee translators will often produce work like Translation I with occasional passages like II, while experienced translators will produce type II translations with occasional lapses into type I. I do not claim that proponents of Model I would recognize Translation $I$ as a good translation, but rather that a translator who consciously or unconsciously sees translating in Model-1 terms is likely to produce a lot of type I translation, even if he or she recognizes that type II is better.

Obviously there are problems that arise in other genres that cannot be illustrated with this text, but I do nevertheless claim that my proposal to encourage translators to regard themselves as rapporteurs is universally applicable. Some may hesitate to look upon the translation of a law, patent or official publication in a bilingual state as a report, since the translation has the same legal status as the original. And many will find it strange to think of the translation of a novel as a report. But this is simply a terminological problem arising from a connotation of the word "report" in every day English ('something secondary'). As I will be showing, a report is by nature a piece of original writing.

\section{REPORTED DISCOURSE AND TRANSLATION}

2.1 Jakobson (1959) says that a translation is a "reported speech: the translator recodes and transmits a message from another source". He does not elaborate, but whatever he actually meant, his language could suggest that the translator (the source of the translation) is a mere receiver/transmitter passing on what the author of the original text (the "other source") has written, through some recoding procedure. This impression is heightened by the fact that reported speech is traditionally viewed as the result of applying to the original text a fairly mechanical set of rules about pronouns and tenses, as in :
(1) A : Why am I doing this?
$\mathrm{X}: \mathrm{A}$ wondered why he was doing that. 
Deeper consideration, however, along the lines of Voloshinov (1973) ${ }^{3}$, suggests that, far from being produced in any such mechanical way, reported discourse is in fact an evaluative analysis by the rapporteur of the original. I now want to explain what I mean by this, using for illustration the case of an imaginary rapporteur $X$ reporting my own words (the first paragraph of section 1.1 of this present article) and the words of R.J. Monneret (the first sentence of the French text in 1.4).

2.2 Beginning with the case of the rapporteur $X$ writing in the same language as the author $\mathrm{A}$ of the original text, we can distinguish direct from indirect reported discourse. In direct reports, $X$ claims to repeat the exact words of $\mathrm{A}$, as in :

(2) X: Mossop said : "Training centres on revision : source text and translation are compared and weak points in technique are brought out".

While A's words (in this example, my own words) are clearly separated from $\mathrm{X}$ 's in (2), and faithfully reproduced, X has nonetheless selected what he or she deemed relevant from all of what A said. Also, A's words must be read in the context of $X$ 's whole discourse, which might have gone like this :

(3) X: Revision is too often described in terms of the translator rather than the customer. Mossop says: "Training centres on revision: source text and translation are compared and weak points in technique are brought out". But the purpose of revision is not training.

What in my original text was an observation about training has been turned into what $\mathrm{X}$ claims is an incorrect view of revision. I did not say or imply that the purpose of revision is training, so $\mathrm{X}$ has distorted the meaning despite the use of direct quotation.

In extreme cases, as in journalism, only one or two words of the original may be cited. But in all cases, $\mathrm{X}$ analyses what the source-text author $\mathrm{A}$ has written, and then makes a selection she or he deems relevant to $\mathrm{C}$. Despite the formal boundary between the voices of $\mathrm{A}$ and $\mathrm{X}, \mathrm{X}$ does intrude (whether in good or bad faith) into the area between quotation marks. And this would be true even if X's entire discourse were to consist of nothing but :

(4) Mossop said: "In my experience as both trainee and trainer, the on-job training and development of translators tends to divorce the question "How do I translate?" from the question "What am I doing when I translate?". The emphasis is on the first question - on technique rather than on purpose. Training centres on revision: source text and translation are compared and weak points in technique are brought out."

This is the full text of the first paragraph of 1.1, but it would still have to be interpreted in terms of X's purpose in writing to $C$, as opposed to A's purpose in writing to $B$. $X$ inevitably causes change by the very act of moving a message into the system $\mathrm{X} \rightarrow \mathrm{C}$ : different individuals with different identities and purposes form the matrix within which the text has meaning.

2.3 Turning now to indirectly reported discourse ${ }^{4}$, we find that the formal boundary between the voices of $\mathrm{X}$ and $\mathrm{A}$ has disappeared :

3. Voloshinov does not discuss translation, but it was his extensive discussion of reported speech that suggested to me the idea of the translator as rapporteur.

4. I use "report" here to cover the whole field that Genette (1972 p. 189-193) divides into "discours rapporté" (style direct), "discours transposé"' (style indirect, style indirect libre), and "discours raconté" (where the words of A no longer have a distinguishable presence). My "indirect report" or "indirect(ly reported) discourse" cover "discours transposé" and "discours raconté" (6) and (7) below are examples of the latter. 
(5) X: Mossop said that in his experience as both trainee and trainer, the on-job training and development of translators tended to divorce the question "How do I translate?" from the question "What am I doing when I translate?".

This exemplifies the traditional notion of indirect discourse, with only the (obligatory) change of "my" to "his" and the (optional) change of "tends" to "tended". But the traditional notion can be extended to cases where A's exact words are forgotten or not deemed relevant, for example :

(6) Mossop said that his experience on both sides of the training relation showed that a separation is made between the question "How do you translate?" and the question "What are you doing when you translate?".

(7) Mossop said that he has found translator training to involve a separation between technique and purpose.

These too are indirect reports, though X's analytical/evaluative work is much more extensive in (6), and especially in (7), than in (5). Note that there is no a priori reason to consider (6) or (7) less accurate as reports of the first sentence of 1.1 than (5). Accuracy cannot be determined by mere linguistic comparison. We have already seen that even directly reported discourse can distort. In deciding whether (7) is accurate, we would have to ask, among other things, whether and to what extent the expression "on-job" in the original was significant. Was the writer making an assertion about on-job training as opposed to other types of training such as university training? If so, the meaning has been distorted in (7); if not, then (7) is an accurate report in that respect.

2.4 In indirectly reported discourse, the introductory phrase "A said that" ("according to $A$ ", and the like) is not essential. The first paragraph of 1.1 could be reported as follows :

(8) [...Mossop made a presentation on translator training.] In his experience as both trainee and trainer, the on-job training of translators tends to separate the question of technique from that of purpose. There is an emphasis on the former. Training centres on revision : source text and translation are compared and weak points in technique are brought out. [...]

If the shift of "my" to "his" is reversed, the result will be a "translation' of the first paragraph of 1.1. An actual (interlingual) translation, I now want to demonstrate, is in principle no different.

Where $\mathrm{C}$ does not understand the language of $\mathrm{A}, \mathrm{X}$ cannot use a direct report. When reporting to such a $C$ the first sentence of the French text in 1.4, $\mathrm{X}$ cannot write :

(9) Monneret said: "Malgré la protection sous ses différentes formes dont jouit le Pèlerin dans notre région, en 1972, une légère rechute inexpliquée est enregistrée."

$\mathrm{X}$ must therefore use an indirect report, but the sort of indirect report exemplified in (5) above, with only formal changes of tenses and pronouns, would give :

(10) Monneret said that malgré la protection sous ses différentes formes dont jouissait le Pèlerin dans leur région, une légère rechute inexpliquée avait été enregistrée.

While (9) could appear in an English text directed to an audience able to read French, (10) is not a possible English text-fragment at all. Yet its very impossibility is illuminating. It shows that in indirectly reporting discourse in another language, X cannot "say what A said", but must use his or her own words. This contrasts with the unilingual situation described earlier, where the possibility of repeating A's exact words is available (though in practice rarely used) : in (8), for example, $X$ chose to repeat A's exact words in the last sentence, though not in the first two. 
So in bilingual reporting, $X$ has no choice but to use a type of indirect report in which more than mechanical tense and pronoun changes are involved. Some possibilities in the case under consideration :

(11) Monneret said that despite the protection in various forms which the peregrine in their region enjoyed, in 1972 a slight unexplained new decrease in numbers had been recorded.

(12) Monneret said that despite the various types of measure taken to protect the peregrine in the region, in 1972 a slight unexplained decrease in numbers had been noted.

(13) Monneret said that in 1972, despite the various protective measures that had been taken, there had been a slight unexplained decrease in the peregrine population in the area.

(14) Monneret said that for some unknown reason there were slightly fewer peregrines in the region in 1972 despite measures taken to counteract such a trend.

(15) Monneret said that by 1972 protective measures had for some reason failed to prevent a slight decrease in the peregrine population in the area.

Reports (11) to (15) can be converted into what we recognize as translations by removing the "Monneret said that" formula and reversing the tense and pronoun shifts - changes required by a superficial difference of convention between translation and naive oral interpretation ( a child interpreting for a New Canadian will use the "A says" formula and shift pronouns).

A more significant difference between interpretation (naive or professional) and translation is that since translators have more time to prepare their reports, it is generally accepted that a translation should be "closer" in some sense to the original than an interpretation. However there is debate over just what that means. In section 4.3, I try to make clear why (11) and even (12) should be assigned no special status as regards "closeness" to the original. We are not hearing the voice of A more immediately when we read them than when we read (13)-(15). In no sense are they "what A said" : as with (13)-(15), the reader $\mathrm{C}$ will take (11) and (12) to be -and try to read them as-reports of what A wrote to $\mathrm{B}^{5}$. Unfortunately for $\mathrm{C}$, the translator who wrote (11) was processing text rather than analysing and reporting the transaction $\mathrm{A} \rightarrow \mathrm{B}$. As a result, the words of (11), though words of the English language, are not the translator's own words : (11) is typical of Translation I in that the compositional structure or 'rhetoric' is still basically French even though the vocabulary and syntax are English. The translator has not fully "carried over" (trans-lated) the transaction $\mathrm{A} \rightarrow \mathrm{B}$ into $\mathrm{X} \rightarrow \mathrm{C}$. The reader $C$ therefore hears a confusing mixture of the voices of $X$ and $A$ rather than clearly hearing $X$ reporting $A$.

(See the end of section 4.3 for further comment on sentence (12) and on the notion of the translator using his or her own words.)

\section{THE TRANSLATOR AS EQUIVALENCE-SEEKER}

3.1 In recent years, the notion of "equivalence" has come to be used to describe the desired relation between original text and translation. Nida \& Taber (1969) speak of "dynamic equivalence... to be defined in terms of the degree to which the receptors of the message in the receptor language respond to it in

5. In Genette's terms, (11)-(15) are all "discours racontés". $\mathrm{C}$ is of course highly unlikely to consciously consider the translation as a report, and may well think of translations in terms of literal correspondences. But that does not change the fact that $\mathrm{C}$ will take the translation to be an answer to the question "What did A write to B?" and anything which is an answer to that question is by definition reported speech. 
substantially the same manner as the receptors in the source language" (p. 24). They explain what they mean by "same" in terms of the preservation of what they call the informative, expressive and imperative (action-eliciting) functions of the text.

Now this concept of equivalence is retrospective: it states what is to have been achieved when the translation is complete. As such, it provides the reviser or teacher, and the translator at the editing stage, with a self-concept or frame of mind that will guide them in what they are doing-something like "I am looking to see whether the informative, expressive and imperative functions of the original have been preserved in the translation".

But such a concept cannot serve translators at the drafting stage, for what they need at that stage is not a concept of what they will have done when the translation is complete, but rather a concept of what they are doing while composing the translation. "I am trying to substantially reproduce the original receptor's response" will not do-first, because it focusses on the experience of the receptors ( $\mathrm{B}$ and $\mathrm{C}$ in Model-2 terms) rather than on the composing activity of the translator $(\mathrm{X})$; and second, because it recognizes the difference between $\mathrm{A} \rightarrow \mathrm{B}$ and $\mathrm{X} \rightarrow \mathrm{C}$ only in a negative way, through the expression "substantially (the same)".

Catford (1965) makes a statement about equivalence that seems to come closer to what is wanted ${ }^{6}$ when he writes: "The central problem of translation practice is that of finding target-language equivalents" (p. 21). From this we can derive a self-concept for the translator that is at least partly in the right form because it focusses on the activity of the translator-something like "I am trying to find target-language equivalents of the source-language expressions". The focus is not on responses or on an achieved state of equivalence, but rather on the search for equivalents, that is, expressions of the target language.

How does one go about "finding equivalents"? Catford gives only a negative answer: one avoids formal equivalents (translating every instance of word " $x$ " by word " $y$ "; always translating a passive verb by a passive verb, and so on). On the positive side, all he (like other writers) does is give examples of good translation, together with technical linguistic statements of the relation between original and translation ${ }^{7}$. This is fine if one is trying to describe the relation between texts and their completed translations, but for the purpose of training or self-improvement in the process of translating, there are real limits to what can be learned from good examples and from the comparative linguistic analysis of such examples. What is needed is a positive general concept of what one is doing while composing a translation.

3.2 We may begin the search for such a concept by trying to analyse the notion "finding equivalents". It soon becomes apparent that the notion can be taken in

6. Catford and Nida \& Taber doubtless have similar views about what constitutes good translation. I am simply attending here to their particular formulations as regards pedagogical value.

7. See Catford p. 73-82; Nida \& Taber p. 33-55 and 120-162 on back-transformation and restructuring; Vinay \& Darbelnet p. 46-55 on modulation, transposition etc. 
two ways. First, it can be taken to mean something like "thinking up some combination of target-language words that are equivalent, by drawing on the lexical and grammatical resources of the target language". Here "find" means "invent" and this is doubtless what happens in translators' minds while they are composing. But how is this invention guided? Since there is no prospect of describing the process by which we "find" words to express our thoughts (as opposed to describing the result of this process), it is hard to see how this sense of "finding equivalents" can be of any pedagogical value beyond the negative one of cautioning against formal equivalents (literalness).

Perhaps then it would be better to turn to a second, more common meaning of "find", namely "locate". The translator could assume that there already exists somewhere a bit of target-language text that has been used by someone in a situation comparable to that of a passage in the source-language text. This gives a very definite idea of what the translator is doing: looking through his or her memory of past texts or the memory of experts in the subject matter of the text; looking through documents on the subject matter; looking through terminology banks or dictionaries (which are basically distillations, so to speak, of previous uses of words).

This view of the translator's activity ties in with two common ideas about translation procedure: that the translator must engage in research; and that the translator should imagine him or herself to be (in Model-2 terms) A directly addressing $C$. The translation will be said to be equivalent to the original if it is the sort of thing that $\mathrm{A}$ (or rather someone like $\mathrm{A}$ ) would have written had she or he been addressing $C$ in C's language. Thus, in the case of the peregrine falcon text, the translator $X$ would try to imagine what an Anglophone naturalist experimenting with the reproduction of falcons would have written in describing this experiment to another naturalist. To do this, $\mathrm{X}$ would not simply sit at his or her desk engaged in verbal introspection. Rather, $X$ would go out and read English articles on the subject, becoming familiar with the terms, phrasings and concepts employed in such writing. $X$ would consult biological dictionaries and ask questions of Anglophone ornithologists.

Does this give us a satisfactory concept of what the translator is doing? The answer, I think, is no. For the results of research into previous writing on a subject, while absolutely essential, can only assist in the process of composition. Equivalents established from already existing texts cannot simply be copied down $^{8}$. This is so not merely because several possible equivalents may have been found and a choice must be made, but also because it may be that

8. Taking an extreme form of this view of the translator as searching for equivalents in past texts, one could imagine him or her wholly outside a transaction between $\mathrm{A}$ and $\mathrm{C}$, merely pasting together found bits of past text. Householder (1971) describes a school exercise in which a student of Greek or Latin is asked to translate a passage from a modern newspaper into a classical language using only phrases found in the writings of one or more specified classical authors. New and student translators who have just discovered the need for research often start looking for "authorities" for almost every word they write (or so it may appear to the reviser or instructor). They seem to be afraid of using their own words. 
nothing that was found (and perhaps nothing that could have been found) is appropriate to the case at hand ${ }^{9}$.

What must be understood is that a particular instance of $\mathrm{X}$ addressing $\mathrm{C}$ to report what $A$ wrote to $B$ is a unique act, different in certain ways from past uses of language in target-culture situations otherwise comparable to it. It is essential to distinguish those aspects of the situation $\mathrm{X} \rightarrow \mathrm{C}$ that are manifest in past texts (certain concepts and terms, a certain social relation between writer and addressee, certain genre characteristics) from those aspects that are original. These original aspects may be more or less striking, but they are always there, and dealing with them requires creativity ${ }^{10}$. The translator is in the position of an engineer who, confronted with the task of building a bridge or dam at a specific location, cannot simply attend to those features of the landscape that are like those previously encountered, but must also attend to what is specific about that location.

To summarize: (1) the advocates of equivalence warn against formalism (imitating the linguistic and rhetorical structures of the source text) and give examples of true equivalence, but they provide no positive self-concept that

9. A great danger in referring to already-existing texts is that translators do not always consider all the characteristics of those texts. Consider one student's translation of the following sentence from an article in the field of meteorology:

Je supposai que dans les nuages stratiformes il se produisait de façon analogue un processus de déclenchement par glaciation.

The translator had come to realize that where French scientific writers frequently use active sentences with the agent "je", "nous" or "on" as subject, English writers prefer passive sentences with the agent unexpressed. The result was :

A similar process of precipitation triggering through glaciation was assumed to occur in stratiform clouds.

The problem with this otherwise admirable translation is that the article in which this sentence appears is autobiographical, as indicated by its title: "L'origine de la theorie des noyaux de glace comme déclencheurs de précipitation - quelques notes autobiographiques". The author of the article is the originator of the ice-crystal theory of precipitation release, and therefore an English active sentence with " $I$ " as subject is called for. The student had formulated a stylistic equivalence: "in scientific texts, French active with agent as subject $=$ English passive with agent unexpressed'. This equivalence had been derived from existing scientific articles, but most such articles are not autobiographical.

The student could of course have applied the concept of equivalence more carefully, but the concept is by nature conducive to such errors because it orients translators toward the expressions used in already existing texts rather than focussing their attention on the text at hand (including parts of it other than the part being translated, such as the title in the case discussed).

In this connection, it may be noted that Catford's formulation of equivalence (a bit of text in one language can be equivalent to a bit of text in another if the two expressions in question are used in situations sharing at least some features) (Catford $1965 \mathrm{p}$. 49-55) is inadequate because it refers to the situations in which an expression is generally used (presumably determined from existing texts) rather than to the specific situation at hand.

10. Indeed, creativity may sometimes be appropriate even for the unoriginal aspects : it may be that certain text features like level-of-language ought not to be or need not be preserved even if they could be. House (1977) calls cases where text features are changed in this way "adaptation", which she distinguishes from translation (eg classics for children). But in all translation, $\mathrm{X}$ addressing $\mathrm{C}$ is different from $\mathrm{A}$ addressing $\mathrm{B}$. All translation involves adaptation. There may be different degrees of change, but there is no qualitative distinction to be made. It is simply that, in some cases, few or no text-feature changes are called for. Text-feature change and the allowable extent of change generally in translation are further discussed in section 4.3. 
will lead to avoidance of formalism in practice. (2) The only interpretation of "finding equivalents" that is pedagogically usable at the drafting stage of translation is one that orients the translator toward seeing the source text as a sequence of expressions to be replaced by expressions from already existing target-language texts, but this is radically insufficient.

\section{THE TRANSLATOR AS RAPPORTEUR}

4.1 Section 2 of this article showed that translating can be seen as reporting. I now want to show why it should be-why the self-concept "I am reporting to $\mathrm{C}$ what $\mathrm{A}$ has written to $\mathrm{B}$ " can be helpful in dealing with the uniqueness of this $\mathrm{A} \rightarrow \mathrm{B}$ and this $\mathrm{X} \rightarrow \mathrm{C}$.

I want first to look at a feature of the rapporteur situation - the difference between $\mathrm{X}$ and $\mathrm{A}$ - that is central to the guiding role of the rapporteur approach. Then I want to show how the concept of reporting provides a criterion of accuracy and a sense of allowable latitude in translation. Finally, I want to illustrate the ways in which the rapporteur approach can help at each stage of translation procedure.

4.2 The difference between $X$ and $A$. It has frequently been observed that there may be no target-culture situation comparable to some aspect of the source situation, so that "cultural footnotes" may have be provided if $\mathrm{C}$ is to understand what A meant. It has also been observed that differences between the sourcetext reader $B$ and the target-text reader $\mathrm{C}$ may call for significant differences between original and translation if equivalence is to be achieved. But what to my knowledge has never been accorded any positive recognition in the literature on translation is the difference between the translator $X$ and the source-text author A.

There may well exist a translator who is like $A$ in some respect, but that may not be true of the particular translator who is doing this translation. He or she may not have been able to come to an understanding of a concept in the source text, or may have understood but been unable to find any corresponding target-language expression ${ }^{11}$. This may be because of lack of access to existing documentation that would explain the concept or provide the target-language expression. It may also be because the concept is to some extent an innovation by $A$, or the concept is old but $A$ has invented a new expression for it even if

11. Sometimes $\mathrm{X}$ may have found an expression but cannot be certain, because he or she does not understand the concept. Consider the following sentence fragment from a text describing a a new type of hydraulic turbine :

Les deux arguments essentiels pour le choix de la turbine dite Straflo (réduction des frais de construction et meilleure stabilité sur le réseau grâce au moment de giration plus grand)...

This topic is not touched on anywhere else in the text, so it is necessary to rely entirely on outside documentation. In an English article describing a straight-flow turbine similar to the one in question, I found the following: "various advantages .... very large inertia ensures stable running and damping of power fluctuations". This clears up the problem of "stabilité sur le réseau". I then looked up "moment of gyration" in the Standard Handbook for Mechanical Engineers and found "radius of gyration" in the index. The referenced section was headed "moment of inertia", and "radius of inertia" was stated to be a synonym of "radius of gyration". On this basis, I decided that "moment de giration" must be the "inertia" referred to in the English article. Someone "like $A$ " would never have to make such a deduction. 
there exists an "expression consacree", : perhaps A enjoys verbal invention, or perhaps A wrote the first thing that came into his or her head and then neglected to edit, or else decided that, given B's knowledge of the subject matter, editing was unnecessary. If $X$ cannot reach $A$ for an explanation of the innovation, or just runs out of time, then $X$ will be in a state of uncertainty.

When I translated the peregrine falcon text, I did a certain amount of research within the time limits available, but that did not make me an ornithologist specializing in birds of prey. Since there is no practical way of organizing translation so that texts are always translated by experts in the field of the text (who will recognize old concepts and terms and be in a better position to deal with new ones), the translator-even the specialist translator-will always be in a position of not being like $\mathrm{A}$ as regards access to conceptual and terminological knowledge ${ }^{12}$. To charge the uncertain translator with incompetence under these circumstances is pointless. Any pedagogy of translation must face the fact that the most difficult problem of learning to translate is precisely that of learning what to do in the face of uncertainty.

Model 2 allows for uncertainty in that $\mathrm{A}, \mathrm{X}$ and $\mathrm{C}$ are not to be interpreted as abstract sending and receiving points for messages. $\mathrm{X}$ is a real particular person who is not like $A$, and not an idealized text-processor with unlimited time and perfect access to all human knowledge. $A$ is not the idealized author of perfectly edited and perfectly standardized texts. And C is someone who is (or can become) aware of the fact that he or she is reading a translation, not an original, and make allowances accordingly ${ }^{13}$.

Let us look at some examples of how uncertainty was dealt with in translating the peregrine falcon text. Consider the expression "couples steriles" at line 43. On first reading, the sentence in question appears to say that pairs of birds incapable of producing had nevertheless reproduced. But French "stérile" has two senses that are relevant here: (i) "infécond", ie, unable to reproduce, said of living things, and (ii) 'improductif', ie, not in fact reproducing (though perhaps capable of so doing), said of land. One possibility in the case at hand is that the author is using the word in sense (ii), but in reference to living things. For it is clear from the text as a whole that the "couples stériles" are the same birds referred to as "couples improductifs" at line 31 (and "couples contaminés" at line 56), the use of different expressions being merely a manifestation of the French rhetorical habit of avoiding repetition (a habit that characterizes French scientific and technical writing as much as other genres).

There could be several reasons why the birds had not reproduced. The ornithologist who asked for the translation informed me that chemical contaminants can make a bird temporarily sterile (unable to reproduce because of a

12. This is not entirely a disadvantage. A translator who is an expert in the field of the text may be more tempted to introduce his or her own ideas.

13. The entirely appropriate goal of writing a translation which "sounds like English" should not be confused with an attempt to actually fool $\mathrm{C}$ into believing that he or she is reading an original. Translations should in my view always be clearly identified as such, with the translator's name where appropriate, even in the official publications of a bilingual state. If this is thought undesirable, then the texts in the two languages should be independently drafted after discussion of the proposed message. 
problem with the reproductive organs). But it is apparent from earlier passages of the article from which the falcon text is drawn that contaminants can have other effects, such as causing the eggshell to be too thin or changing the behaviour of the mother so that she herself breaks the shell or abandons the eggs (ie, she may produce fertile eggs but fail, nevertheless, to reproduce). Thus the birds were not necessarily sterile in the English sense which, according to Webster's, emphasizes the absence of fertility (ie, in a biological context, English "sterile" would not normally be used in sense (ii) of French "stérile").

How then to render "couples stériles" in English? One possibility is that there is a technical term "sterile pairs" that has just the meaning required here. However I was not able to determine whether this is the case ${ }^{14}$. Being uncertain, I had to assume that if I wrote "sterile pairs", it might well be taken in the ordinary English sense "unable to reproduce", which would be non-sense. That is why I wrote (see Translation II) "formerly unproductive pairs", an expression which fits into the pattern of meaning embodied in the text.

Consider also "double ponte" at line 24 . The meaning is easily deduced from the description of the experiment. It could be an ornithological term or it could be an ad hoc invention by the author. The simple solution was to use my own words - the ordinary English expressions "lay a replacement clutch" and "lay twice". Later at line 44, I used the related expression "lay a second clutch" to translate "recycler". This is a case of a verb being used in a sense not recognized in the standard French dictionaries. It could of course be a special ornithological term, with an equivalent in English, but I had not determined this to be the case, and it was not hard to see how the obvious intended meaning could come about as an extension of the standard meaning.

Finally, consider the expression "toutes conditions d'environnement (dérangements, contamination chimique, etc.) étant constantes par ailleurs" (lines 54-6). I did not manage to determine to my own satisfaction what exactly the author meant by this (how it fitted into his argument). One solution would have been to omit it from the translation, since the notion in question does not appear to be essential (it is expressed in a grammatical parenthesis and is not mentioned elsewhere in the article). Another solution, illustrated in Translation II, is the insertion of question marks in the translation. The significance of both these solutions, in Model 2 terms, is that if $\mathrm{C}$ has asked $\mathrm{X}$ what $\mathrm{A}$ wrote to $\mathrm{B}$, but $\mathrm{X}$ does not know, then $\mathrm{X}$ should not pretend to know. In cases where uncertainty is much greater than it is in this example, dictionary equivalents

14. I could in theory have asked the ornithologist who requested the translation whether "sterile pairs" was suitable. However it is often difficult to interpret the answers to such oral questions. "Yes" in this case could mean "yes, I will understand" or "yes, that is the term that has the required meaning" or, in the case of people who know some French, "yes, what you say conforms to my notion of what a translation is" (a notion which will often be thoroughly misguided). It must also be borne in mind that there is a limit to how much time one can spend asking questions. When the translation, as in this case, is not for publication, one has to select the most important points, and I decided that this point was not as unclear as certain others in the article. Specialized translations which are for publication should be read by an editor who is thoroughly familiar with the field. The translator cannot substitute for an expert editor. 
of the words (what some call a literal "translation") can be added in a translator's footnote ${ }^{15}$.

An understanding of the difference between $\mathrm{A}$ and $\mathrm{X}$ can give the translator the confidence to make the kinds of decisions illustrated above. Note how the decisions were arrived at by seeing the text not as a sequence of expressions, each to be replaced by an equivalent (what someone "like $A$ " would have written), but rather as embodying a pattern of meaning which is being reported to $\mathrm{C}$ and to which each expression (word, phrase, sentence) is a contribution.

4.3 Accuracy and allowable latitude in translation. One reason the concept of reporting, unlike that of equivalence-seeking, is potentially of pedagogical value is that reporting is a part of everyone's experience. Everyone has reported the words of another. And so a thorough explication and definition of the concept is not needed before it can be implemented for training or self-improvement.

From our everyday experience of answering the question "what did so-andso say to so-and-so?" we can derive a sense of what counts as an accurate report and how much latitude we have - the point at which the translator is intruding in an unacceptable manner with his or her own ideas and feelings. In the view being put forward here, such intrusion cannot be eliminated and, furthermore, the goal is not to reduce intrusion to a minimum : there must be a positive intervention by the translator/rapporteur if the meaning of what $\mathrm{A}$ wrote to $B$ is to be fully transferred to the new situation $X \rightarrow C$. Failure to intervene sufficiently results in undertranslation (incomplete transfer) and sometimes mistranslation.

A report can be said to be accurate if it is appropriate, that is, if it contains, explicitly or implicity and in a form suitable for addressing this $\mathrm{C}$, all of what is relevant in $\mathrm{A} \rightarrow \mathrm{B}$ to $\mathrm{C}$. (The provision "form suitable for addressing this C' allows for addition of material that is neither explicit nor implicit in $\mathrm{A} \rightarrow \mathrm{B}$ where that is necessary if $\mathrm{C}$ is to understand $\mathrm{A} \rightarrow \mathrm{B}$ reasonably easily.) This means that something may be "lost in translation" (or added in translation) without that affecting accuracy, so long as the something in question is not relevant to $\mathrm{C}$ (or is relevant in the case of additions). Relevancy is defined not by the source text but by the translator. He or she is being paid precisely to make this decision.

Consider the word "Jura" at line 35 of the falcon text. Since B is probably a resident of France, he or she will recognize "Jura" as the name of one of the

15. New and student translators frequently fail to consider omission as a translating strategy. I once translated a text on the causes of avalanches which began with a description of how the scientist arrived in a nice little Alpine village : the cattle were coming home and there were some pretty flowers growing in the meadows. The author then proceeded to name these flowers. As any one who has translated biology texts will know, it can be extremely difficult to determine the right English common name of an animal or plant given only the French common name. Since this was not a biology text, however, I decided that the names of the flowers were irrelevant, and simply left them out. (Later on, I deleted the entire passage about the village because its personal and anecdotal quality was foreign to comparable English scientific writing.)

Question marks and translator's footnotes should be kept to a minimum but they need not be seen as undesirable, even in work that is to be published. In the Model-2 conception of translation, it is after all the translator who is addressing the reader and it is perhaps even a good thing to draw the reader's attention to this fact, which is what footnotes and question marks do. 
"départements" of France. However, C in the case at hand was an Anglophone Canadian who might well have taken the translation "Jura" to be a reference to a mountain range. And the translation "department of Jura" might have sent him to the dictionary to look up "department" - an unnecessary interference in his reading of the translation. Nothing relevant would be lost if this geographical reference were simply omitted. Another possibility-which I selected in this case - was the translation "province of Jura". In this text, the different constitutional statuses of French departments and Canadian provinces is utterly irrelevant. In a political science text comparing the constitutions of Canada and France, "province of Jura" would of course be a major mistranslation ${ }^{16}$. Note again that such matters will never be considered if the translator is processing expressions sequentially (here "la ponte de 3 œufs du site B1 (Jura)") instead of attending to the whole pattern of meaning being conveyed to $\mathrm{C}$.

While I am claiming that the concepts of accuracy and allowable latitude are derivable intuitively from our everyday experience of reporting what others have said, that does not mean that these concepts need no further explicitation. It would be helpful to define reporting in relation to other sorts of writing, in terms of the relative roles of X's imitation of A and X's inventing activity - the relative roles of the voices of $X$ and $A$. In our culture, a false dichotomy is made between original and unoriginal writing, with translationeven literary translation-in the latter category. But in fact no writing is completely original, and all writing contains some degree of originality, whether it be trivial or significant, highly valued by society or not.

Consider in this connection some of the traditional questions that are asked about translation. Should the translation reflect the style of the original or the style of the translator? Should it add or omit conceptual material or not add or omit such material? These questions pose false dichotomies. The answer to both of them is: it depends. And Model 2 makes this explicit: it depends on what the transaction $\mathrm{X} \rightarrow \mathrm{C}$ calls for, on what is relevant.

Take the first of the above questions. Suppose the source text is an unedited piece of psycho-sociological prose replete with empty jargon. It may be appropriate to reflect this in the translation, or conceal it and state the author's argument with minimal jargon, or use a mixture of both these strategies (especially if the original does not merely show lack of editing but actual wooliness of thought, so that it is hard to determine the author's argument) ${ }^{17}$. All these

16. It is true that "province of Jura" may give $\mathrm{C}$ the mistaken impression that France has provinces like Canada, but that is just one of the risks involved in getting information second hand from a translator (assuming that $\mathrm{C}$ does not want a translation that is loaded down with explanatory footnotes: "department-an administrative district of France"). If $\mathrm{C}$ wants to avoid such pitfalls, then he or she will just have to learn the French language and the cultures of the peoples who speak it. Like any report, a translation is second best (even if, in the case of poorly written source texts, it may in some ways be an improvement on the original). And like a report, a translation can sometimes be quite useless: an Anglophone supervisor cannot for instance evaluate the writing ability of a Francophone employee on the basis of a translation of a sample of the latter's work. This becomes apparent if we substitute "report" for "translation": if one wants to see whether A is capable of explaining something in writing, one does not ask for a report of A's explanation, since what is relevant in A's text will inevitably be lost.

17. It is easier to improve than to reflect low-quality writing because the translator cannot use the excuse of badly written French to write gallic "English". Bad English writing must still be 
possibilities are allowed for in the notion of a report. In the falcon text, I decided that it was necessary to paraphrase lines $21-33$ in order to properly bring out the argument, which remains obscure in Translation $I^{18}$.

Aside from the matter of reflecting (insofar as possible) or changing the source-text author's personal style, there is the problem of whether to preserve certain more general rhetorical characteristics of the text. For example, much French scientific writing contains features of literary style and these must on no account be reflected in English. To do so would create the impression that the source-text author is an amateur dabbler in science, for literary rhetoric is rare in English scientific writing nowadays. At the opposite extreme, I have translated scientific texts which are transcripts of speeches given by scientists and therefore contain features of oral language (frequent interjections; changes of grammatical structure in mid-sentence; detours from and sudden returns to the main argument which were signalled by intonation or gesture when the speech was given but are not represented in the written transcript; and of course colloquialisms). Since the translation of such texts is generally requested for the purpose of determining the scientific content, preservation of these features of oral language is pointless, and any attempt to do so would be a waste of time.

Turning now to the question of whether conceptual material can be added or omitted, I think most would agree that some types of addition and omission are warranted : semantic material that is implicit in the original may be made explicit and material which is explicit in the original may be left implicit. Least controversial will be the mere omission of excess verbiage : writing "extinction" rather than "extinction of the peregrine" to translate "l'extinction de notre Pèlerin" at line 7 of the falcon text. Then there is omission by summarizing: lines 55-8 of the falcon text are translated "our previous conclusion was confirmed" in Translation II. One result of summarizing in this case is that the birds are not referred to as "contaminated" (line 56 of the French), but then contamination of the birds is discussed elsewhere in the text and is not relevant here.

As regards addition of material, an uncontroversial type is exemplified at line 12, where "over the birds" makes explicit an idea that is implicit in the French. Then there is addition of the type illustrated at lines 41-2: the parenthesis "(bris de coquille)" cannot be satisfactorily rendered "(broken shell)", and in Translation II it is expanded on the basis of information from an earlier part of the article (not given in the passage reproduced in 1.4). More contro-

English : the translator would have to figure out how a bad English writer, as opposed to a bad French writer, would convey an idea, and this could be very time-consuming especially if, as is probably the case, the translator is a fairly good writer. This is not to say that gallicisms are always bad: they might in some instances be useful for reminding the reader that the reported text comes from another culture.

Obscurity in the source text may of course result not from poor writing habits but from the author's desire to be vague, in which case it must be reflected in the translation.

18. The argument is: (i) If eggs are taken into captivity, will that reduce the population in the wild? (ii) Determine this by experiment : see if wild birds will lay a second clutch of eggs. (iii) This experiment may itself reduce the population. (iv) To prevent this, carry out the experiment on birds that have not been reproducing anyway. 
versial no doubt are additions like "province of Jura" which are based on the needs of the reader $C$.

Controversy over allowable omissions and additions sometimes takes the form of accusing the translator of rewriting rather than translating, and so we must ask the question : at what point does translation become non-translation? I do not think any hard and fast borderline can be defined, anymore than one can say at what point water being heated in kettle changes from cold to hot. However, just as there are clear cases of hot water, so there are clear cases of non-translation. For instance, the following is not a translation of lines 43-46 of the falcon text:

(16) Thus, sterile pairs appear to recover from contamination and start laying fertile eggs again, and they can lay a second clutch which is more viable than the first.

The idea expressed in (16) may be perfectly true, but (16) is nevertheless a nontranslation (indeed, a mistranslation) - not because it wrongly analyses the vocabulary and syntactic structure of the French, but because there is no textual evidence in this passage (or elsewhere in the article) that the idea it expresses is that of the source-text author. It is thus not a report.

But now consider the following as a translation of the sentence beginning at line 34 :

(17) In 1973 the eggs were taken from two nests : 3 from site B1 in the province of Jura and 2 from site D1 in Haute-Savoie within a week of the day on which the last one was assumed to have been laid, because after that the time the female's ova would be resorbed.

The idea expressed in (17) is true, and moreover it is based on the article - the sentence immediately following the passage reproduced in 1.4 reads : "Cependant quelques précautions nous paraissent indispensables: - la collecte des œufs doit se faire dans un délai de 8 jours maximum après la ponte du dernier œuf, sous peine de ne pas obtenir la deuxième ponte souhaitée (régression des grappes ovariennes chez la femelle); ...' In my view, (17) is not a mistranslation. The fact that the point about ova resorption is not made at line 37 but later in the article is not particularly relevant in this genre of writing. However (17) is a non-translation because the procedures which translators commonly use will not normally result in something like (17). Rather (17) is the sort of thing that might result if the translator worked by taking notes (mentally or in writing) on the French text and then composing an English report from the notes. And such a difference in the order of presentation of points would almost certainly result if a Francophone and an Anglophone, both working on Project Peregrine, were asked to independently do a write-up on the project, one in French and the other in English.

Consider the following text which I composed from "mental notes" following careful reading of the first half of the source text (looking back at the French only once, between drafting of the two paragraphs) :

Project Peregrine was a response to the decline in the peregrine falcon population in the Jura region in 1972 following several years when the outlook had been more hopeful. To prevent any further reduction in the population, or extinction, it was decided to breed falcons in captivity and then return them to the wild if the environmental conditions improved, that is, if factors responsible for the decline (chemical pollution is one possibility) were identified and dealt with. 
Before we removed any eggs from nests for this purpose, we had to be certain that this would not itself affect the number of birds living outside captivity. We therefore took eggs from pairs who had not recently had success in reproducing anyway, and then checked to see whether the female would lay a replacement clutch. Results were encouraging :...

If I were to complete this report-from-notes and compare the result with Translation II, the two most noticeable differences would be: (i) many points in Translation II are dealt with more briefly in the report-from-notes, or in the case of minor points not dealt with at all, and (ii) there is a major rearrangement of points. Had I been a member of Project Peregrine and written up a report based on my own experience and discussion with other members of the project, the differences would have been greater yet : both texts would likely contain points missing in the other. Nevertheless, there might still be a high degree of equivalence, in that the same main points would probably be made.

Thus pairs of equivalent texts are of several kinds which, while distinguishable, are not separated by any hard and fast boundaries. Equivalence may be achieved by independent drafting based on shared experience and discussion; or it may be achieved by reporting, either from notes on a source-text, or directly from the source-text itself. It is the latter type of report which we call a translation. Because it is composed by working directly from the source text, a translation is characterized by a high level of relatively clear correspondences to expressions of the source text. (Correspondences can of course be clear even if there is little matching in the order of expressions within sentences, and even if the meaning of a source-text expression is spread over words in separate parts of the translation.) There may be some summarizing (as at lines 52-3) or some re-arrangement of ideas that goes beyond changing the order of expressions within a sentence (the paraphrase at lines 21-33). But these are occasional features of translations.

Implicit in this view of the difference between translation and non-translation is that there may be cases where a source text is so badly written, or written in such an idiosyncratic style, that a report-from-notes rather than a report-fromtext (a translation) is called for. A report-from-notes will be the natural approach if the person requesting the translation explicitly asks for a summary or précis, but the translator may also begin by reporting-from-text and then find that what is in fact called for is a précis or extended paraphrase. Finally, there may be cases (advertising texts for example) where for cultural reasons it is best not to work from a source text at all but to prepare an independent draft.

Clearly more needs to be said about the extent of rearranging, paraphrasing and summarizing allowable in a translation. But from a pedagogical point of view, the great danger is not an overly liberal approach but rather an overly conservative one. New and student translators do indeed often make leaps in the dark and invent things that have no textual support. But more often they fail to go far enough.

Consider again sentences (11) to (15) in section 2.4 (ignoring the introductory formula and the tense changes). Some might argue that only (12) is a translation "proper" and that (13), and certainly (14) and (15), are something else. The 
meaning of this argument would, I think, be that (12) is the translation least likely to contain errors: (15) may at first appear to express the same ideas as the French, but, according to this argument, there is a greater risk that the meaning has unwittingly been changed.

This notion that the "least risk" translation will be one which closely approximates the compositional form of the original-minus gross stylistic infelicities such as those in (11) - is thoroughly misguided. Translations like (12) are no more proof against error than translations like (13)-(15). This is so because overattention to compositional form does, in practice, divert the translator's attention from meaning and give rise to undertranslation:

- It leads to nonsense: "sterile pairs" at line 43 of Translation I of the falcon text (always assuming that this is not a technical term); "it thus appeared clear... that the replacement clutches appear more productive" at lines 52-8.

- It leads to translations that make perfect sense, but the wrong sense: " 15 days" at line 38 and " 8 days" at line 36 , both of which create the impression that a very precise number of days is involved, when in fact the meaning is "two weeks" and "one week".

- It results in losing the structure of an argument: see lines 21-33 of Translation I and note 18.

- It results in unenglish rhetoric that may confuse the reader: the repetition at lines 55-8 of the conclusion of the experiment, already given at lines 43-6; the reference to the same birds as "unproductive pairs" (line 32), "contaminated pairs" (line 55) and "sterile pairs"; the use of parentheses in " 40 days instead of the normal 15 to 18 (broken shell)" (line 41).

A good report can certainly contain sentences that turn out to be similar in compositional form to sentences in the French. But the status of such sentences is no different from that of sentences which are not similar in this respect. They may be appropriate for reporting to $\mathrm{C}$ what $\mathrm{A}$ has written to $\mathrm{B}$, or they may not. The principle "as free as necessary, as literal as possible" is a bad one: there is no merit in being as literal as possible, and as noted above, it can be dangerous. As it happens, translation (12) is not too bad, but to rely on translations like (12) is simply to abdicate the translator's responsibility to decide how to report to $\mathrm{C}$.

Overuse of "close" translations like (12) is a result of translators' seeing themselves not as writers but as text processors. In describing translators as writers, I am referring to the fact they must, as I said in 2.4, use their own words to deal with the unique transactions $\mathrm{A} \rightarrow \mathrm{B}$ and $\mathrm{X} \rightarrow \mathrm{C}$. The notion of undertranslating (just discussed) and the notion of $\mathrm{X}$ being different from $\mathrm{A}$ (discussed in section 4.2) together provide a definition of what "own words" means: the translator must neither mimic the compositional structure of A's French writing nor try, by copying down equivalents established from already-existing texts, to mimic the text which an Anglophone writer "like A" might have produced. The latter sort of mimicry is just as formalistic as the former: it transports forms from other texts into the text being composed without sufficient regard for their appropriateness to the pattern of meaning being conveyed to $\mathrm{C}$. 
Translators have been seen and have come to see themselves as subordinate to something that already exists and need only be mimicked. Translation I of the falcon text shows the result of subordination to compositional structure (the source-text sequence of expressions) though it does not illustrate the far more complex type of self-subordination that occurs when the translator tries to become "like A" through overuse or misuse of conceptual, terminological and stylistic research. Such self-concepts stand in the way of successful translation. During training, they need to be replaced by the concept of the translator as writer.

4.4 Translation procedure. In Model 2, French-to-English translation is seen as an exercise in English composition - the writing of a report-rather than an exercise in textual processing and comparison. Because a report is necessarily a report to someone, translators who see themselves as rapporteurs will, I think, tend to adopt translating procedures more attuned to the needs of the reader $\mathrm{C}$ than translators who see themselves as text-processors looking for equivalents. The rapporteur approach can help at all three stages of translation : pre-drafting, drafting and editing.

4.4.1 The pre-drafting stage. It is often said that before drafting begins, the translator should read the source text over and perhaps carry out a certain amount of conceptual and terminological research. But if the translation is to be a good one, an additional preliminary step is required, one that follows from a Model-2 focus on specific social relations rather than on the text per se.

The step in question is that of holding a consultative interview with the requester of the translation (who may be $\mathrm{A}, \mathrm{B}, \mathrm{C}$ or a fourth party), much as a doctor would interview a patient, or a plumber a homeowner. The purpose of the interview is to determine the identity and needs of $\mathrm{C}$. Is $\mathrm{C}$ a known individual or group, or does $\mathrm{C}$ include unknown individuals (the users of a certain library where the translation will be deposited; the reading public generally)? If $\mathrm{C}$ is one individual, it may be appropriate to interview him or her at some point in the translation process; certain decisions can then be made on the basis of whether that particular individual will understand.

The interview with the requester or with $\mathrm{C}$ may also reveal that a précis will do instead of a full translation, that only a part of the text need be translated, or other information that may save the translator a great deal of research and writing time.

In many cases, of course, the answers to the interview questions will be evident or known from past experience, so that the interview will be unnecessary. But it is needed in principle, and under no circumstances will a translator operating under Model 2 see his or her ideal to be that of not "bothering" the requester. One cannot write for $C$ unless one knows enough about C's identity and needs to determine what is relevant to $C$. Perhaps the most important thing about the interview is that it gives the translator a sense of audience. This is important if the translation is going to sound like someone writing to someone else with a purpose in mind. Translation $I$ of the falcon text fails in this respect. When $C$ reads such a translation, he or she may come to doubt $\mathrm{X}$ 's ability or-if $\mathrm{C}$ is less sophisticated about translation-to feel that the 
source-text author A "must be a very strange person to write that way". The principle cause of bad writing is not failure to apply the so-called rules of good English usage but rather failure to be constantly aware of one's audience.

4.4.2 The drafting stage. The great danger at the drafting stage of translation is that because of the slow speed of work, as relatively small bits of text are dealt with one after the other, the translator will lose track of the overall movement of both the source text and the translation that is coming into being. He or she may unconsciously begin to work in terms of the questions "What does this expression mean?" and "What is the English for it?"-questions which imply the existence, quite separate from the present transactions $\mathrm{A} \rightarrow \mathrm{B}$ and $\mathrm{X} \rightarrow \mathrm{C}$, of universally valid answers lying 'out there' somewhere (in a source-language dictionary or a target-language encyclopedia article for instance) ${ }^{19}$. The result will be the gallic and choppy sort of writing that comes from failing to see beyond the linguistic and rhetorical form of the bit of text being processed, and from trying to piece together the translation bit by bit out of material from a variety of sources.

The questions a rapporteur will ask are: "What does A mean by this expression?" and "What words shall I use to appropriately address C at this point in this paragraph of this translation?". Both questions pertain to the contribution of expressions to what $I$ have called the pattern of meaning (which the source-text author has built up, and which the translator is now reconstructing for C). The translator-rapporteur who is puzzled by an expression will not rush off to dictionaries and other reference materials but instead will try to figure out what A meant through consideration of what A was saying in the rest of the text, supplementing this process where necessary by searches in extratextual material.

To some extent, perhaps, the constant to-and-fro between source text and translation creates problems that cannot be resolved until the editing stage. However I think a Model-2 focus on the participants A, B, X and C can reduce the incidence of such problems. The translator who sees him or herself as a rapporteur will feel less impulse to begin by writing or even thinking pseudoEnglish sentences of the sort that appear in Translation I, because the idea of reporting will focus attention on the author's meaning rather than on the series of expressions that form the text. Sentences can then be cast in suitable syntactic and rhetorical shape right from the start, requiring tidying-up but not total recasting at the editing stage 20 .

19. An important feature of Model 2 is that it contains no disembodied entity called "meaning". This is because the meanings translators are concerned with are inseparable from specific texts and speakers : not dictionary meanings or meanings found in already-existing texts. It is also worth noting that the "meaning" of Models 1 and la has no pedagogical value, because students cannot be asked to construct in their heads a meaning which has no linguistic (textual) form.

20. I have mentioned that the drafting stage inevitably proceeds quite slowly and that this can cause the translator to lose sight of the overall flow of both source text and translation. Drafting can be speeded up to some extent if the translator does not insist on getting every nuance just right at this stage, but instead concentrates on getting the sentences cast in proper shape, with a reasonably good approximation to the right meaning. The editing stage can then be used to increase the degree of equivalence. Two examples: (i) Lines 8-10 of Translation II originally read: "the cause may have been the use of a new and as yet unidentified chemical". I decided during editing to render French "dispersion" more closely and wrote "the cause 
The proper psychological approach here can be backed up by the mechanical technique of keeping one's eyes off the French while thinking about and writing down the English. If one is staring at the words "malgre la protection sous ses différentes formes...", one is much more likely to sink into mechanical text-processing and think "despite the protection in various forms..."; and if one is operating under Model 1, a "translation" such as this may receive validation from the text-fetishism inherent in that model: English facsimiles of the linguistic or rhetorical structures of the French may come to be seen as magically carrying the French meaning along with them. The translator who instead sees him or herself as writing a report will be more conscious of the need to analyse and evaluate, to look behind these structures.

Only an experiment could tell whether a Model-2 approach makes drafting slower than it would be using Model 1 . But even if it does, less work will be required at the editing stage. Indeed, if most sentences have been badly cast during drafting, as in Translation I, it will not only be time-consuming to repair problems at the editing stage, but there will be a great temptation to leave unchanged what in fact requires changing. Translation I does not call for editing but for retranslation (Translation II is definitely not a revised form of I). One should never begin by deliberately writing sentences that are "close to the French", because the habits of French composition are very different from those of English, with the result that a good percentage of the sentences, even though grammatically correct, will need extensive reworking.

4.4.3 The editing (revision) stage. At this stage, there are two texts in front of the translator, so that the notion of checking for equivalence now has its place. However, this is not the sole function of editing. Just as important is the reading of the completed translation from the point of view of the reader $\mathrm{C}^{21}$. During editing, the translator is trying to determine whether C's implicit question "What did A say to B?" has been adequately answered.

To look at the text from C's viewpoint, the translator must read it as an English composition, without referring to the French (to which $\mathrm{C}$ has in

may have been a new and as yet unidentified chemical entering the environment". Later it occurred to me that I might have written "spreading through the environment", but the distinction between entering and spreading is not relevant here : the point is that the pollutant got to the eggs; the "spreading" can be deduced from Translation II as it stands. (ii) At line 45 , I originally wrote "better results", thinking that English "viable" would be a faux ami, since it usually means "practicable". During editing, I decided to look into this more closely, and discovered that English "viable" has a special meaning in biology ("having developed sufficiently within the uterus or egg to be able to live and continue normal development outside"). As it turned out, then, there was no faux ami problem. However, "better results" does convey the meaning, and because the danger of faux amis is so great in translation between English and French, it is just as well to avoid using cognates of French words during drafting. At line 7 , for example, "catastrophic" would be too strong. As it happens, I had originally written "disastrous", so that there was no problem needing detection during editing.

For an interesting published example of this sort of revision work, see Hébert and Scott, Dialogue sur la traduction (Montréal, Éditions HMH, 1970), which contains two revisions by Scott of his translation of Hébert's poem «Le tombeau des rois».

21. The translator cannot duplicate C's response because he or she will be different from $\mathrm{C}$ in significant ways. This is not a problem peculiar to translation. No writer can be certain how readers will respond, but of course the whole purpose of editing is to reduce the writer/reader gap, to find things that will mislead or annoy the reader. 
principle no access). As the translation is read over a couple of paragraphs at a time, linguistic matters such as spelling, grammar and usage can be dealt with, but also, and perhaps more importantly, rhetorical matters such as overly wordy sentences and inter-sentence and inter-paragraph transitions and coherence. For instance, at lines $24-6$ of the falcon text I originally wrote "the first thing we had to do was determine whether birds in the wild would lay a replacement clutch". But a reading of the English text as a whole showed that there was no "second thing" that had to be done before proceeding with Project Peregrine. The use of the word "first" in the sense "being number one in a series" was thus incorrect. In Translation II, I used "first" in a different and appropriate sense ("beforehand"), though it could also have been omitted.

Several sorts of problems are less likely to be noticed if this step in revision is omitted. Sentences like "Despite the protection...", if these were not avoided during drafting, may escape notice. And consider Translation I of the two sentences beginning at line 11 of the falcon text :

At any rate, this possibility remained as a permanent potential threat. That is why, looking ahead to further threats, it was decided...

Here the drafter, attending only to the word "menace" in the French, has mechanically repeated the noun "threat" in the second sentence. But there is something odd about using "threats" without mentioning who or what is threatened. This problem could be corrected by adding "to the birds", but the plural "threats" is itself problematic because (unlike "threat" in the first sentence) it suggests a human agency expressing an intention to do harm. Moreover the very repetition of the same noun is in this case not very felicitous. The first two of these problems will be most noticeable if one is reading whole sentences rather than comparing isolated expressions with the French, and the third if one is reading whole paragraphs without pausing after each sentence to look at the French. An improvement might be :

That is why, looking ahead to further problems, it was decided...

A further improvement would be the elimination of "that is why", which is just excess verbiage in English (however one might judge the stylistic value of "c'est pourquoi" in the French). Again, this is more likely to be noticed if the sentence is read immediately after the previous sentence. In this connection, it may be of interest to note that Translation II (see lines 11-14) began with a better draft in the first place, one that combined the two sentences :

Since this possibility hung as a permanent threat over the birds, it was decided to guard against further hazards by...

After a couple of paragraphs of the translation have been read without reference to the French, they can then be gone over a sentence or so at a time and compared with the French for equivalence. During comparison, it is again important to read the English first. If the French has been read just seconds before the corresponding part of the translation, the translator will tend to think that the meaning being derived from the reading of the English is coming from that reading, whereas in fact it is coming into his or her mind from the just previously read French text. As a result, the translator will be much less likely to notice flaws in the translation that may bother the reader $\mathrm{C}$. 
In this comparison step of revision, there is the danger of making changes which introduce error or leave errors uncorrected. This can be avoided if, as at the drafting stage, each sentence is regarded not as a sequence of expressions but as a contribution to a pattern of meaning. Consider, in connection with the two sentences discussed above, the common type of editorial change which consists in replacing two or three words by one. Thinking "en prévision de" = "in the expectation of", we might write :

That is why, expecting to further problems, it was decided...

Note that the word "to" has not been deleted: a surprisingly common editorial error is that of failing to make additional changes required by some initial revision. Also, those who object to all instances of "dangling participles" will note that this has been left uncorrected. Both are problems of the sort that arise when attention is being paid not to a whole sentence but to its disembodied parts and their individual correspondences with the French.

A third problem is that "expecting" suggests that chemical contamination was being predicted (foreseen as probable rather than possible). This might be thought to be the correct interpretation, given the dictionary definition of "en prévision de", namely "en pensant que telle chose arrivera" (Robert). The author's argument would then be : 'the possibility of contamination was foreseen and, expecting that contamination would indeed occur, we decided to...'. But is that the meaning (or the only meaning) that fits the pattern of the text as a whole? Another interpretation is in fact possible, and just as consistent with the dictionary, which defines the verb "prevoir" as meaning either "considérer comme probable" or "organiser d'avance". The author, having dealt with the possibility of problems in the previous sentence, could now be talking about something to prevent disaster. In other words, his argument could be: 'The possibility of contamination was foreseen and, to prevent population reduction in the event of such contamination, we decided to...'. So an alternative revision might be :

That is why, to forestall further problems, it was decided...

I personally favour this latter interpretation, but the point here is that interpretation in the light of the whole text is essential; the dictionary definitions of isolated expressions do not resolve anything. Having noted the two possible meanings, one might fudge by omission ("That is why it was decided...") or perhaps by writing "in anticipation of", which could be taken to mean either "expecting" or "to forestall" (though some might be more inclined to one of these interpretations rather than the other). The original draft "looking ahead" perhaps has both meanings as well. Note that "problems" is nicely vague and suitable for either interpretation : it can be taken as meaning either "(expecting) occurrences of contamination" or "(to forestall) reductions in the bird population'".

Conclusion. In this section, I have tried to flesh out the concept of the translator as rapporteur. A rapporteur is someone unlike the source-text author $A$ who is asked by someone else to tell $C$ what $A$ wrote to $B$; who reads what $A$ wrote, determining the pattern of relevant meaning; who drafts a reportfrom-text in his or her own words in a manner appropriate to $C$; and who 
finally edits the report, comparing it with the source-text pattern of meaning and reading it as an English composition whose aim is to answer C's original question.

\section{SOURCES OF RESISTANCE TO MODEL 2}

In this last section, I want to suggest that Model 1 is not merely one view of translation among others but that it reflects what might be called the linguistic culture of our society. Four aspects of this culture will be considered: the impact of telecommunications technology on our understanding of what "communication" is; the role of the common cultural artefacts known as dictionaries in determining our ideas about "meaning"; the conception of "good writing" which we derive from various sources claiming cultural authority in matters of language; and finally the notion of "other languages" that is embodied in the pedagogy of second-language learning, in bilingual dictionaries and terminology banks, and in the methodology of machine translation.

5.1 "Communication": the technological model. The telecommunications and data processing technology of our society influence the way we think about linguistic transactions between people. Telecommunications are communications only in the very narrow sense that symbols are moved from one place to another. That is why, in describing Model 2, I have avoided words like "communication" and "information", using instead "transaction", "what A wrote to B" and "what A meant".

The central problem in information-moving is how best to get the most information from one location to another with minimal interference and at least cost. The content, purpose and effect of the material being moved are irrelevant. And while one terminal of a communications link may be labelled with the name of the human source of the information, and the other terminal with the name of the human destination, the labels serve mnemonic purposes only. The identities and purposes of the "communicators" are extraneous. The interaction between them has no relevant social qualities whatever; all that is relevant are the physical entities moving between them.

The translator in Model 1 is a mover of information in an analogous sense: one who sees the meaning which is to be moved from $A$ to $C$ as already existent (in the source text), so that it need only be transferred through the physical substitution of equivalents in C's language. What happens in Model 2 is quite different, in that meaning has to be constructed in the process of $\mathrm{X}$ addressing $\mathrm{C}$.

Telecommunications and data processing involve the transcoding of messages according to a completely predetermined system, as when letters are converted to holes on punch cards, or speech to electrical impulses in a telephone system. While we all know that translation cannot be like this, there being no code for converting a French text into an English one, the search for equivalents in Model 1 is conceived on the model of codes - even if the code in question is not as simple as in keypunching. Harrap's dictionary may then be used as if it were a codebook, or at a more sophisticated level translators may assume that equivalents for source-text expressions already exist in articles or the heads 
of experts in a given field (ie, a transcoding exists but has not yet been recorded in a dictionary/codebook).

I would even go so far as to suggest, not completely unseriously, that the habit of paying and evaluating translators by the number of physical words they translate is derived from such communications models as keypunching or telegram encoding. Certainly those who pay translators high salaries must yearn to find a way of reducing the translation process to a transcoding one.

5.2 "Meaning": the dictionary model. In section 4.4 I pointed out that translators are constantly being tempted to ask themselves "what does this word mean?" rather than "what did this writer mean (by using this word)?". The very idea of asking what isolated words mean comes to us in part from our experience of using unilingual dictionaries, one of the functions of which is generally thought to be precisely that of answering this question.

Now an article in a dictionary may contain two types of information related to meaning : definitions and citations. The biggest versions of a dictionary will give several definitions (the several senses of the word), each of which will be accompanied by citations - examples of the use of that word in the given sense. However the abridged versions (those we first used and often still have on our desks) not only reduce the number of different senses of the word, but more importantly cut down both the number and the length of citations, often substituting short hypothetical examples for longer citations from real texts. Sometimes the shorter versions of dictionaries eliminate citations altogether.

This feature of abridged versions is due to the definitions' being seen as central : definitions answer the question "what does this word mean?". But in reality, definitions are derived by dictionary-makers from the citations which they have collected. Examples of actual uses of a word are grouped into a number of senses, and then a definition is written for each sense. The structure of a dictionary article makes it appear as if each word has a small and precise number of distinct senses, when in fact there is a whole range of senses in which the word has been used, and the dictionary-maker has simply grouped certain senses together, making more or fewer distinctions depending on the size of the dictionary.

Thus the smaller dictionaries, which are most widely available, give us less of an appreciation of what people have actually meant by using words (as represented by the citations). They lead us instead to think of words as "having meanings" (as represented by the definitions).

I do not deny the validity of asking what words mean, but the important question for translators is what the writer meant by using a certain word in a specific passage. What words mean, and what people mean by them on particular occasions, are two different things.

A final point worth making about dictionaries is that some are more normative than others, and record not so much what words mean as what the "linguistic establishment" of a society thinks they ought to mean. Normative dictionaries are therefore not as valuable as usage-oriented dictionaries when it comes to determining the source-text author's meaning. 
5.3 "Good writing": the "correct usage" model. It is a feature of our linguistic culture that good writing is often discussed in terms of the presence or absence of something called "correct usage". A curious thing about debates on this subject is that the examples discussed are mostly single words (eg "hopefully"), sometimes short expressions (eg "consist of" vs "consist in") and occasionally syntactic structures (eg dangling participles). The focus is on small, disembodied bits of language rather than on the text as a whole. The question tends to be "should one write this or that" rather than "is this or that appropriate in this case?".

To take an example, the unreasoned fixation of purveyors of "correct usage" on the grammatical number of nouns can place roadblocks in the way of conveying the semantic distinctions appropriate to a given context. The insistence that the English word "data" is plural (on the absurd ground that the Latin word "data" was plural) prevents making the distinction "the data have been wrongly entered on the cards" vs "the data you sent us is quite useless", where in the former case individual datums are being considered but in the latter the datums are seen as forming a whole.

This approach to writing is a manifestation of that central aspect of our linguistic culture that looks for automatic text-processing rules, in this case to promote successful communication through absolute standardization (the proposed standard being dubbed "correct" as a means of exerting moral and social pressure to use it).

Because good writing tends to be discussed in terms of rules for words or short expressions, other aspects of good writing get neglected: the importance of inter-sentence and inter-paragraph coherence, and more generally the structure of whole texts; the importance of tailoring what one writers to one's audience, and more generally the place of creativity in good writing. Indeed, the notion of a single standard for written English is incompatible with the idea of adaptation to audience (and to the intent of the source-text author). To take another example from the realm of grammatical number, it may sometimes be appropriate to avoid sentences like "anyone wishing to cash his cheque should do so now" and one way of accomplishing this without resort to the awkward "cash his or her cheque" is to write "cash their cheque". But this is claimed by some to be bad English because "anyone" is grammatically singular. The use of "their", which is common in spoken English, is a creative application of the structure of the language: our plural pronouns are genderneutral, so they can be used to refer to persons previously referred to by indefinite pronouns in contexts where one wants to avoid specifying sex.

The whole obsession with correct usage that regularly manifests itself on the letters-to-the-editor pages of our daily newspapers reflects a view of language as an alien object whose laws are written in stone and must be obeyed by us. The alternative is to see language as a part of ourselves and to see ourselves as text-creators, not mere assemblers of ready-made ways of writing. The expressions appropriate to a specific situation do not already exist; we must at least to some degree invent them. 
5.4 "Other languages": three models of automatic correspondence. How we translate depends to some extent on how we conceive the relation between our own language and others. That conception is greatly influenced by the way we learned second languages, and is reinforced by the nature of the bilingual dictionaries that are widely available (most recently in the form of handheld electronic devices). In addition to these two factors, which influence the public generally, translators' ideas of how other languages are related to their own are influenced by technological developments such as computerized bilingual terminology banks and machine translation.

5.4.1 Second-language learning. Many of the defects of Translation $I$ of the falcon text will be recognized as the sort of thing we all wrote when we were learning French at school and doing the exercise misleadingly called "translate into English". The purpose of that exercise was to demonstrate to the teacher that we had mastered certain vocabulary items and certain syntactic structures of the other language. To demonstrate this, we were expected to "translate" on the basis of a primitive version of Model 1 in which the relation between a French text and an English text is pictured as a set of one-to-one correspondences between words and between syntactic structures.

Thus at line 2 of the falcon text, we would have demonstrated that we knew the meaning of "notre" by writing "our", despite the stylistic infelicity that results ${ }^{22}$. And for the sentence beginning at line 8 we would have written what appears in Translation I; Translation II fails since "cause" rather than "dispersion" is the subject of "may", contrary to the French, and there is no way of knowing from Translation II whether the student knows the meaning of "écart".

Often (especially in modern languages as opposed to Latin and Greek) the material the teacher gave us to "translate" was a series of contextless sentences. We were not translating a coherent sequence of utterances that an actual person had written to some actual audience on some real occasion. Thus we were not translating in the sense in which professional translators translate. Rather we were doing what linguists call "glosing": writing something that gives an idea of the structure of the source language items that are present. Some teachers treated even coherent texts on the model of such isolated sentences, and there is a great temptation to carry this practice over into professional translation.

Our early experience of "translation" cannot but continue to have a mental hold on us and this will be particularly true when on-job training is done on the reviser system. The reviser may simply take the place of the teacher, with the translator writing not for the intended reader but for the reviser. There may be subtle pressure to make the translation parallel the compositional form of the original in order to make the work of the reviser easier.

5.4.2 Bilingual dictionaries and terminology banks. The idea that there exist direct correspondences between the expressions of one language and those of

22. Translation II renders "notre région" as "the area". It is clear from the article (of which the text in section 1.4 is a passage) which area is meant. But that is irrelevant from the point of view of traditional second-language pedagogy. 
another is embodied in and derived from bilingual dictionaries. We were all exposed to simple forms of such dictionaries when we were learning French: vocabulary lists that told us that "pauvre = poor" and "chat = cat". Such equations suggest that it is not necessary to figure out what the author of a source text meant by an expression; one can go directly from source language to target language by making the appropriate substitutions.

Harrap's is of course much more sophisticated; it gives a list of equivalents, often with distinguishing context : homme pauvre = poor man, pauvre d'esprit $=$ dull-witted, minerai pauvre en métal $=$ ore with a low metal content ${ }^{23}$. But the form of these statements (if not the intent) still suggests automatic equivalents : if "pauvre" appears with "minerai", use "low"; if it appears with "esprit", use "dull". Like the high-school vocabulary list, Harrap's simply tells us how expressions have commonly been translated. Such dictionaries are often called translating dictionaries, but this is sometimes taken to mean that they give translations. In fact, all they can do is suggest possible translations, for the question always remains whether any of the equivalents listed is suitable. To decide this, the translator must have first determined the meaning of the expression as it is used in the text at hand. Bilingual dictionaries can of course assist in this determination of meaning, but unilingual dictionaries are better for this purpose because they provide definitions and citations, whereas bilingual dictionaries convey meaning much more indirectly - through target-language words whose meanings are presumed to be known.

But what of specialized terminologies? Is it not possible to determine automatic equivalents within special subject fields? In principle there is a distinction between a dictionary and a terminology listing in that a unilingual dictionary is constructed by working from an ambiguous linguistic form to its many meanings, while a unilingual terminology listing is constructed by working from one set notion to its corresponding term and a good bilingual terminology is based on two such unilingual listings. But from the point of view of the translator, a bilingual terminology - whether in book or printout form -is just a specialized bilingual dictionary. It is true that within a specialty field it is often legitimate to make statements of the form "such and such an object is called $\mathrm{x}$ in English and $\mathrm{y}$ in French". But however legitimate such statements may be, they do not automatically resolve the question of how to translate a text containing the expression y into English.

23. Consultation of a good bilingual dictionary (and certainly a unilingual dictionary) might have prevented the translation "appear" at line 43 of Translation I of the falcon text. Harrap's might have suggested "sterile pairs are apparently able"; Robert-Collins might have suggested "sterile pairs turn out to be". Similarly, "la ponte de remplacement semble plus viable" at line 45 and "il nous est donc apparu probant" at line 52 might have been better rendered, perhaps as "it seems that the replacement is more viable" and "this looked to us like convincing evidence". Translation II takes a different approach, using "suggest" in connection with the 1973 experiment and "confirm" in connection with the 1974 experiment.

Neither Harrap's nor Robert-Collins would have been much help with "autochtone" at line 15 , where the translator has fallen prey to the temptation to use a Greek-based word, perhaps in the (false) belief that this is how English-speaking scientists write. Both dictionaries give only "autochthonous" and "native"; the latter is only a slight improvement and would still not be satisfactory. 
The translator must first decide whether the expression in the source text is in fact being used in the special sense the terminologist has discovered. It may not be clear whether it is being so used, because the source-text writer may not be writing in accordance with the intra- and inter-linguistic standards that are implicit in the ideal form of terminology lists. Different writers (or one writer in different articles or different passages of a given article) may use varying expressions, some of them ad hoc inventions, for the same concept. And writers often fail to edit what they have written in accordance with standards, where these have been established. Given the lack of standardization (which is of course reflected in the results of good terminological research), and given the fact that even the most careful writing has a degree of imprecision, it would seem unwise to overemphasize the possibility of finding "the one right term" even in specialty fields. As far as scientific writing is concerned, it would on the contrary be prudent to recall that as each science has developed beyond a certain point, its practitioners have found the need to abandon language, with all its imprecision, in favour of mathematics.

Beyond the question of the possibility of finding "the one right term", there is the matter of the importance of so doing. Consider the case of "viable" at line 45 of the falcon text. My draft translation "better results" was perfectly acceptable because the technical term "viable" (see section 4.4 note 20) was not really essential in that particular passage. And as pointed out in section 4.2, "sterile pairs" may be a technical term in English, but it was not really essential to find out. Even if the translation had been for publication, "formerly unproductive pairs" would have been perfectly adequate.

With the prospect of deskside access to terminology banks on the horizon, it cannot be overemphasized that the basic problem of translation is not that of finding "right terms". The basic problem is deciding how to convey to $C$ what A has written to B. My experience as a reviser and as an instructor in a university translation program suggests to me that, while it is important to make translators aware of terminology as a problem, this can come into conflict with the more important task of getting them to concentrate on the specificity of the text and the passage at hand. Students of translation seem to be particularly prone to demanding a universally applicable "rule" for translating a given expression. The findings of terminologists may at first appear to supply such rules, but in fact they do not. There are no rules for translation. At most there are rules-of-thumb : for a given source-language expression there may be a target-language expression which often or almost always works as its translation. But even these rules-of-thumb can never substitute for a consideration of the specific passage at hand, and of what is appropriate in addressing the intended reader of the translation.

5.4.3 Machine translation. Great efforts have been expended over the past thirty-five years to find a way of programming computers to translate, so far with rather limited success.

Now anyone who wants to pursue this task has no choice but to work solely in terms of text processing, ignoring the human participants. This is so because existing machines have no social identity or purposes and are not participants in 
a culture; all they can do is process text items according to a fully explicit set of rules.

The very earliest attempts at machine translation were by engineers. In 1947 Warren Weaver asked whether the problem of translation could not be seen as a problem of cryptography. "When I look at an article in Russian," he wrote to Norbert Wiener, "I say: "This is really written in English, but it has been coded in some strange symbols. I will now proceed to decode.", (Weaver 1955).

Attempts at word-by-word transcoding were of course a failure. The next step was to pay attention to the grammatical structures of sentences. Finally, it was realized that the machine would somehow have to look at surrounding sentences and even at aspects of the extratextual situation. But how could the machine be given this knowledge in the form of explicit rules that identify source-text items and give predetermined equivalents on the basis of features of the context and situation?

Dansereau (1978) gives a clear non-technical picture of just what some of the problems encountered are. How, for instance, do you make sure that a machine translating an aircraft manual does not render "during the ground test stand clear of aircraft" by "Durant le sol vérifier le banc à l'écart de l'avion"? As it happens, this problem can be solved purely in terms of the grammatical structure of the sentence.

But what about ensuring that "check the cable guide for proper installation" comes out as "vérifier l'installation du guide du câble", whereas the structurally similar "check reservoir for leaks" comes out as "vérifier qu'il n'y a pas de fuite au réservoir"? To translate correctly, with "pas", the machine must somehow "know" that a leak is a bad thing. Dansereau neglects to point out that this is knowledge of a non-linguistic nature. It is no part of the dictionary meaning of "leak" that a leak is a bad thing. A leak is certainly a defect, but while a defect in an aircraft may be a bad thing for an aircraft maintenance man, it may be a good thing for someone else, say a terrorist. If "check reservoir for leaks" appeared in a terrorists' manual, it might have to be translated "vérifier qu'il y a bien une fuite au réservoir".

The present machine translation approach to this difficulty is simple : write a program that can translate a maintenance manual but nothing else. The entry for "leak" in the machine's vocabulary will then contain the non-linguistic information "bad thing", thus triggering "pas". The machine will be left in ignorance of any other possibility; it will select the right answer because it will not be allowed to consider any wrong answers.

To give the machine a more universal capacity, so that it could decide for itself whether a leak was a bad thing or a good thing in a specific case, it would be necessary to supply it with explicitly formulated knowledge about the worldabout maintenance and about terrorism. The machine could then make inferences ('terrorists sabotage planes - a plane may be sabotaged if equipment is made defective - a leak is a defect-therefore a terrorist might want to cause a leak'). Such a machine would in some sense be intelligent. It might be able to 
figure out simple extensions of meaning like that of "recycler" discussed in section 4.2. But so far, this is just a dream (Wilks 1978).

The point of the above simplified - but I believe not essentially misleading account of machine translation is this : unlike the programmer of a translating machine, a human translator has no need to acquire any explicit rules for dealing with the world outside language or for dealing with linguistic structures. As a participant in a human culture, he or she already has access to both these types of knowledge and already knows how to combine them to interpret a text. Very little is known about how people do this. It is a matter of the greatest interest to psychologists, linguists and researchers in the field of artificial intelligence. But it is of no interest whatever to human translators as such. If we knew the mental processes by which people interpret and write, that would not improve human translation one iota, any more than our ability to breathe would be improved by taking a course on the anatomy of the respiratory system.

I think it fair to say that the persistence of Model 1 conceptions of translation has its roots in machine translation, in the need to formulate explicit rules for extracting meaning from texts and synthesizing equivalent texts. This is a need which human translators do not have. Indeed, any search for rules, any attempt by the translator to conceive of him or herself as a text processor, will hinder the use of the natural abilities to interpret language in context and to report what others have said. The result will be bad translation. What is required is for the translator to progressively refine these natural abilities, and I suggest that one way to do this is to use and develop the concept of the translator as rapporteur.

\section{FINAL WORD}

This article has been about translator training. But I am of course making more than just a pedagogical claim. I am not simply suggesting that translators can produce work like Translation II of the falcon text by thinking of themsleves as rapporteurs. I am also implicitly making the normative claim that if a good report-from-text is written (as described in section 4.3), then the result should be considered a good translation. In other words, I have simply assumed readers will agree that Translation I is bad translation and not a report, that Translation II is by and large a good translation and a good report, and that training should take the production of type II translations as its goal. Some may not agree, but that is another matter.

\section{REFERENCES}

CATFORD, J. (1965) : A linguistic theory of translation, London, Oxford University Press.

DANSEREAU, J. (1978): "Traduction automatique et terminologie automatique», Meta 23(2), Montreal, Presses de l'Université de Montréal.

GENETTE, G. (1972) : Figures III, Paris, Seuil.

HOUSE, J. (1977): $A$ model for translation quality assessment, Tübingen, TBL Verlag Günter Narr.

HOUSEHOLDER, F. (1971): "Corrections, revisions and centos", chapter 15 of Linguistic Speculations, London, Cambridge University Press. 
JAKOBSON, R. (1959): "On linguistic aspects of translation", in Brower (ed), On Translation, Cambridge, Harvard University Press.

MOSKOWITZ, D. (1973): "Le traducteur: récepteur et destinataire du message", Études de linguistique appliquée 12, Paris, Didier.

NIDA, E. and C. TABER, (1969) : The Theory and Practice of Translation, Leiden, E.J. Brill. VINAY, J.-P. and J. DARBELNET (1967) : Stylistique comparée du français et de l'anglais, Montréal, Beauchemin.

VOLOSHINOV, V. $(1930,1973)$ : "Toward a history of forms of utterance in language constructions", part III of Marxism and the Philosophy of Language, New York, Academic Press.

WEAVER, W. (1955): "Translation", in Locke and Booth (eds), Machine Translation of Languages, Technology Press of MIT and Wiley \& Sons, New York.

WILKS, Y. (1978): "Four generations of machine translation research and prospects for the future", in Gerver and Sinaiko (eds), Language Interpretation and Communication, New York and London, Plenum.

WILSS, W. (1977) : Übersetzungswissenschaft, Stuttgart, Verlag Ernst Klett. 